\title{
Design of a Dual-polarization Dual-band MIMO Antenna for Wireless Applications
}

\author{
Xiaoying Ran ${ }^{1}$, Jingxin $\mathrm{Wei}^{1}$ and Zhen $\mathrm{Yu}^{1,2}$ \\ ${ }^{1}$ North China Institute of Science and Technology (NCIST), China \\ ${ }^{2}$ Beijing University of Posts and Telecommunications (BUPT), China
}

\begin{abstract}
A compact dual-polarization dual-band planar antenna with two orthogonal stubs structure is proposed for MIMO mobile handsets in the paper. The antenna can cover more than ten mobile applications in dual-bands with -6dB bandwidth of $34 \%(1.987-2.8 \mathrm{GHz})$ for TD-SCDMA $(2.3-2.4 \mathrm{GHz})$, WCDMA (1.92-2.17GHz), LTE33-41 (1.9-2.69GHz), ISM2.4GHz (2.4-2.4835GHz), WLAN (802.11b/g/n:2.4-2.48GHz), Bluetooth, GPS, COMPASS, GLONSS, GALILEO and $38.6 \%$ $6.449 \mathrm{GHz})$ for WLAN $(802.11 \mathrm{a} / \mathrm{n}: 5.15-5.35 \mathrm{GHz})$, ISM5.8GHz $(5.725-5.85 \mathrm{GHz})$ wireless applications. The antenna is fabricated on a $1.6 \mathrm{~mm}$-thick FR4 substrate with dielectric constant of 4.4 , and the size is $100 * 100 \mathrm{~mm} 2$. The good agreement between the measurement results and the simulation validates the proposed design approach and meets the requirements for various wireless applications.
\end{abstract}

Keywords-dual-polarization; dual-band; compact antenna; MIMO

\section{INTRODUCTION}

Miniaturized multi-broadband planar Multiple-Input Multiple-Output (MIMO) antennas have been widely used in mobile terminal devices in recent years. In order to better achieve the multiband and miniaturization, many technologies have been studied, such as coupling feed technology [1-3], slot loaded technology [4-5], loading the matching network [6], and loading printed distributed inductance technology [7] and fractal technology [8]. Inverted L-slot patch with a defected ground plane is used for triple-band operation in [9], whereas three circular-arc-shaped strips whose whole geometry looks like "ear"-type antenna are reported to cover the desirable bands for WLAN/WiMAX wireless communication terminal in [10]. A square slot, a pair of L-strips, and a monopole radiator are used to excite three different resonances in [11]. A microstrip feed line, a substrate, and a ground plane on which some simple slots are etched to achieve triband operation in [12]. The requirement of dual polarization is added in the antenna technology in [13-15]. In [16], dual-element antenna arrays for small devices of MIMO applications which have semi-printed structure, and operate in ISM $2.4 \mathrm{GHz}$ band as well as between 5 and $6 \mathrm{GHz}$. Several works have proposed adding slots in the PCB to realize wave-traps [17-18].

In this paper, a dual-polarization planar antenna with two orthogonal branches structure is proposed and designed for wireless communication systems that can support dual-band applications. The antenna covers more than ten mobile applications of TD-SCDMA(2.3-2.4GHz), WCDMA(1.92-
2.17GHz), LTE33-41(1.9-2.69GHz), ISM2.4GHz(2.4$2.4835 \mathrm{GHz})$, WLAN $(802.11 \mathrm{~b} / \mathrm{g} / \mathrm{n}: 2.4-2.48 \mathrm{GHz})$, Bluetooth, GPS, COMPASS, GLONSS, GALILEO, WLAN(802.11a/n:5.15-5.35GHz), and ISM5.8GHz(5.725$5.85 \mathrm{GHz}$ ) wireless applications.

\section{Antenna Structure And Design Procedure}

\section{A. Characteristics of Antenna Structure}

The configuration of the proposed antenna is shown in Figure I with dimensions in Table I. The antenna has two orthogonal branches structure radiator with a rectangle slot in one branch. The antenna is designed on FR4 substrate with height of $1.6 \mathrm{~mm}$, dielectric constant ( $\mathrm{\varepsilon r}$ ) of 4.4 and loss tangent $(\delta)$ of 0.02 .

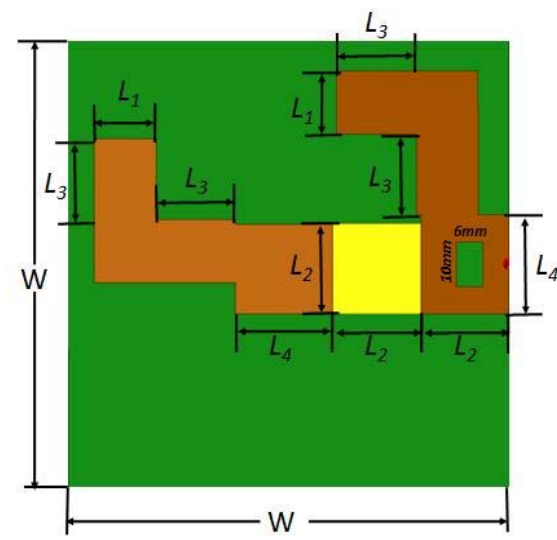

FIGURE I. LAYOUT OF PROPOSED ANTENNA.

TABLE I. DIMENSIONS OF PROPOSED ANTENNA (MM)

\begin{tabular}{ccccc}
\hline $\mathbf{W}$ & $\mathbf{L}_{\mathbf{1}}$ & $\mathbf{L}_{\mathbf{2}}$ & $\mathbf{L}_{\mathbf{3}}$ & $\mathbf{L}_{\mathbf{4}}$ \\
\hline 100 & 14 & 20 & 18 & 22 \\
\hline
\end{tabular}

\section{B. Performance of Simulation}

The simulation is conducted by Ansoft HFSS 15.0. Figure II illustrates the reflection loss (S11) curves at different branch lengths and widths. Figure III shows the voltage standing wave ratio (VSWR) curve of the antenna.

It can be seen that the proposed antenna can operate at dual-bands centered at $2.3 \mathrm{GHz}$ with $-11.55 \mathrm{~dB}$ reflection loss and $5.15 \mathrm{GHz}$ with $-10.61 \mathrm{~dB}$ reflection loss. The simulated - 
$10 \mathrm{~dB}$ bandwidth is $252 \mathrm{MHz}$ for the first band (2.159$2.411 \mathrm{GHz}$ ) and $274 \mathrm{MHz}$ for the second band (5.026$5.3 \mathrm{GHz})$.The simulated $-6 \mathrm{~dB}$ bandwidth for the first band $(1.987-2.8 \mathrm{GHz})$ is $34 \%$ and the second band $(4.364-6.449 \mathrm{GHz})$ is $38.6 \%$. These bands cover several commercial application bands of $3 \mathrm{G}, 4 \mathrm{G}, \mathrm{WiFi}$, Bluetooth and navigations, as given in Table II, III

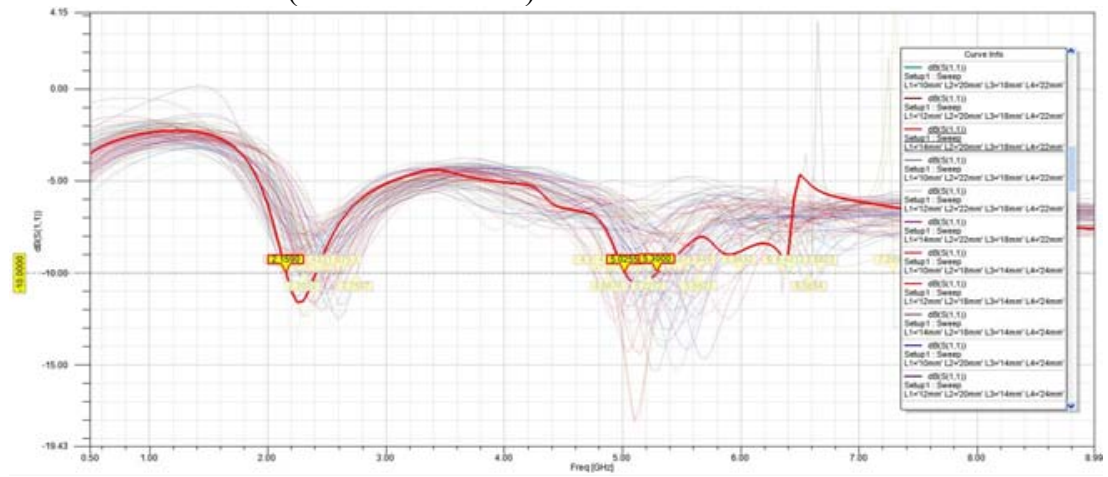

FIGURE II. COMBINED SIMULATED REFLECTION LOSS AT DIFFERENT L

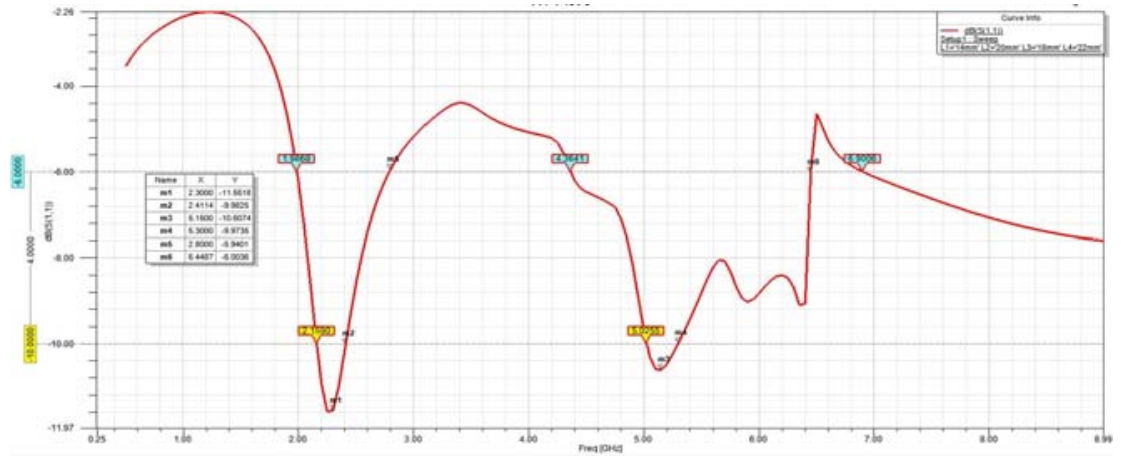

FIGURE III. SIMULATED REFLECTION LOSS OF THE PROPOSED ANTENNA

TABLE II. -10DB FREQUENCY BANDS COVERED BY ANTENNA

\begin{tabular}{|l|l|l|}
\hline Band No. & -10dB Bandwidth & Covered Commercial Bands \\
\hline 1 & $2.159-2.411 \mathrm{GHz}$ & $\begin{array}{l}\text { LTE40,TD-SCDMA, ISM2.4GHz, } \\
\text { Bluetooth }\end{array}$ \\
\hline 2 & $5.026-5.3 \mathrm{GHz}$ & WLAN $(802.11 \mathrm{a} / \mathrm{n}: 5.15-5.35 \mathrm{GHz})$ \\
\hline
\end{tabular}

TABLE III. -6DB FREQUENCY BANDS COVERED BY ANTENNA

\begin{tabular}{|c|c|c|}
\hline Band No. & -6dB Bandwidth & Covered Commercial Bands \\
\hline 1 & $\begin{array}{l}1.987-2.8 \mathrm{GHz} \\
(34 \%)\end{array}$ & $\begin{array}{l}\text { TD-SCDMA(2.3-2.4GHz), } \\
\text { WCDMA(1.92-2.17GHz), LTE33- } \\
41(1.9-2.69 \mathrm{GHz}), \text { ISM2.4GHz(2.4- } \\
2.4835 \mathrm{GHz}), \\
\text { WLAN(802.11b/g/n:2.4- } \\
\text { 2.48GHz),Bluetooth, GPS, } \\
\text { COMPASS, GLONSS, GALILEO }\end{array}$ \\
\hline 2 & $\begin{array}{l}4.364- \\
6.449 \mathrm{GHz}(38.6 \%)\end{array}$ & $\begin{array}{l}\text { WLAN(802.11a/n:5.15-5.35GHz), } \\
\text { ISM5.8GHz(5.725-5.85GHz) }\end{array}$ \\
\hline
\end{tabular}

The surface current amplitude distribution on radiator of the proposed antenna that work at the center frequency of $2.3 \mathrm{GHz}$ and $5.15 \mathrm{GHz}$, respectively, are shown in Figure IV. For $2.3 \mathrm{GHz}$ frequency, the current is more concentrated at the distal part of the radiator, as shown in Figure IV (A). As the frequency increase, the proximal part of the radiator has more current, as shown in Figure IV (B).

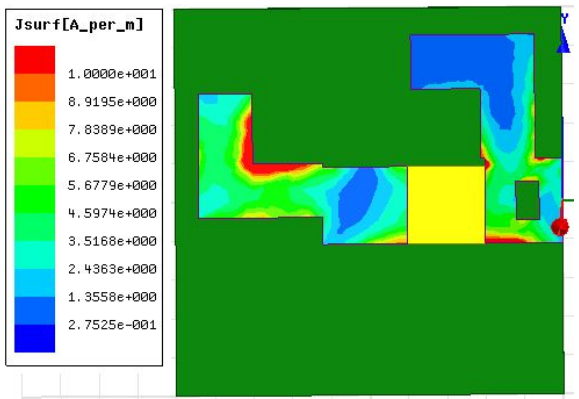

A) $2.3 \mathrm{GHZ}$

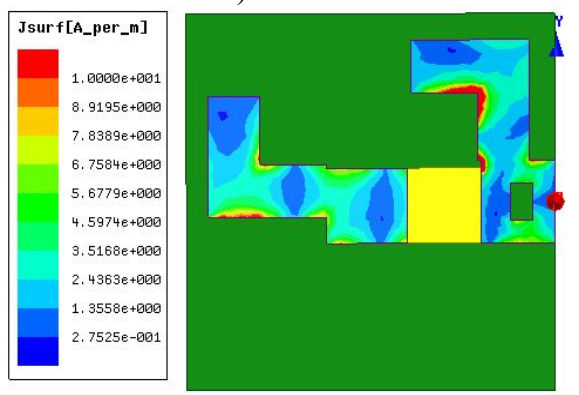

B) $5.15 \mathrm{GHZ}$

FIGURE IV. CURRENT DISTRIBUTION OF THE ANTENNA AT DIFFERENT CENTER FREQUENCIES 
The simulated E/H-plane and 3D radiation patterns of the proposed antenna at the center frequencies of $2.3 \mathrm{GHz}$ and $5.15 \mathrm{GHz}$ are shown in Figure V. It can be seen that the patterns are close to omnidirectional at all bands.

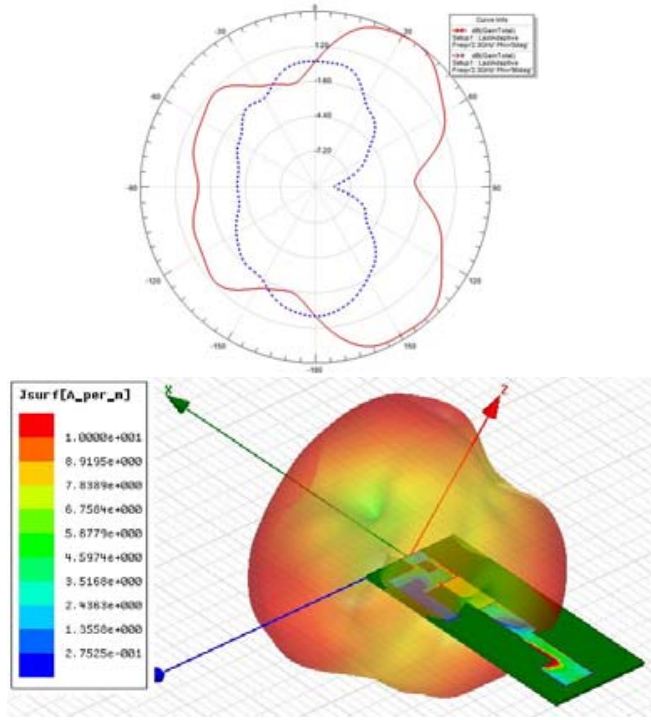

A) $2.3 \mathrm{GHZ}$

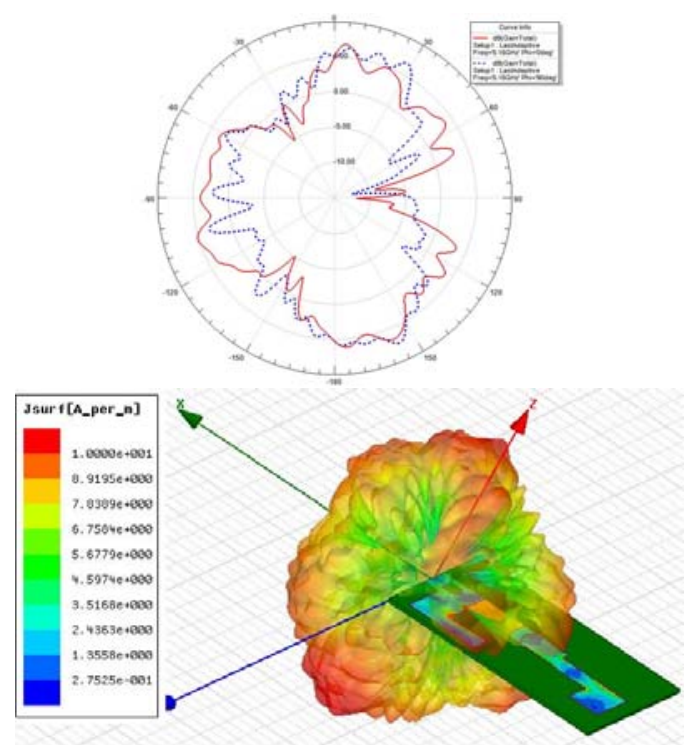

B) $5.15 \mathrm{GHZ}$

FIGURE V. SIMULATED E/H-PLANE AND 3D RADIATION PATTERNS AT DIFFERENT FREQUENCIES

\section{FABRICATION AND MEASURED RESULTS}

To verify the dual-band performance of the MIMO antenna, a prototype antenna is fabricated and measured. The antenna is built on $1.6 \mathrm{~mm}$ thick FR4 substrate with loss tangent $=0.02$ and $30 \mu \mathrm{m}$ copper, as show in Figure VI. The antenna is tested by antenna measurement system of PNA3621.

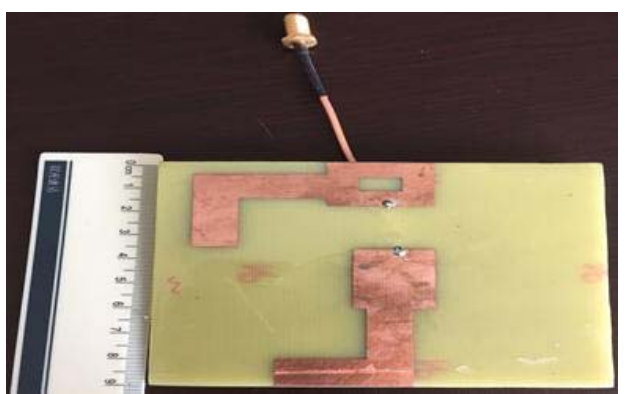

FIGURE VI. FABRICATED ANTENNA PROTOTYPE

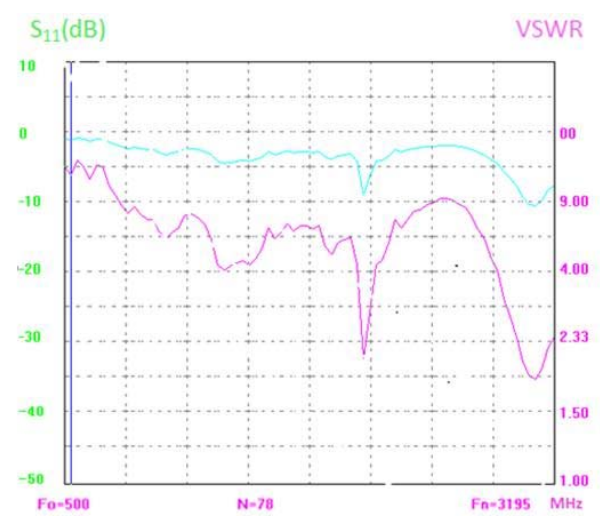

FIGUREVII. MEASURED S11 AND VSWR CURVES

The measured reflection loss $\left(\mathrm{S}_{11}\right)$ and Voltage Standing Wave Ratio (VSWR) have better agreement with the simulated results, as shown in Figure VII. This makes the antenna compatible for mobile communications applications.

\section{CONCLUSIONS}

A novel compact dual-polarization planar antenna with two orthogonal branches structure is developed for TD-SCDMA, WCDMA, LTE, ISM2.4/5.8GHz, WLAN, Bluetooth, GPS, COMPASS, GLONSS, GALILEO wireless applications. The better agreement between the measurement results and the simulation validates the proposed antenna meets the requirements for various wireless applications.

\section{ACKNOWLEDGMENT}

This work was financially supported by LangFang Science and Technology Research and Development Project (No.2016011007, No.2016011006), Scientific and Research Project of Central Universities of NCIST (No. 3142013051) and Educational Science Research Project of NCIST (HKJY201411, HKJYZD201310).

\section{REFERENCES}

[1] D.G. Kang and Y. Sung, "Coupled-fed planar printed shorted monopole antenna for LTE/WWAN mobile handset applications," IET Microwaves, Antennas and Propagation, vol. 6, no. 9, pp. 1007-1016, 2012.

[2] Z. L. Xie, W. B. Lin, and G. L. Yang, "Coupled-fed printed antenna for LTE mobile handset applications," Microwave and Optical Technology Letters, vol. 56, no. 8, pp. 1752-1756, 2014.

[3] J. H. Chen, Y. L. Ban, H. M. Yuan, and Y. J. Wu, "Printed coupled-fed PIFA for seven-band GSM/UMTS/LTE WWAN mobile phone," Journal 
of Electromagnetic Waves and Applications, vol. 26, no. 2-3, pp. 390401, 2012.

[4] Z. Chen, Y.L. Ban, J. H. Chen, J. L.W. Li, and Y. J. Wu, "Bandwidth enhancement of LTE/WWAN printed mobile phone antenna using slotted ground structure," Progress in Electromagnetics Research, vol. 129 , pp. 469-483, 2012.

[5] M. T. Wu, and M. L. Chuang, "Multibroadband slotted bow-tie monopole antenna," IEEE Antennas and Wireless Propag. Lett., vol. 14, pp. 887-890, 2015.

[6] Y. L. Ban, Y. F. Qiang, Z. Chen, K. Kang, and J. L.W. Li, "Lowprofile narrow-frame antenna for seven-band WWAN/LTE smartphone applications," IEEE Antennas and Wireless Propag. Lett., vol. 13, pp. $463-466,2014$.

[7] C. H. Chang and K. L. Wong, "Small-size printed monopole with a printed distributed inductor for pentaband WWAN mobile phone application," Microwave and Optical Technology Letters, vol. 51, no. 12, pp. 2903-2908, 2009.

[8] C. L. Nóbrega, M. R. Silva, P. H. Fonseca, et al, "Simple, compact, and multiband trequency selective surfaces using dissimilar Sierpinski fractal elements," International Journal of Antennas and Propagation, pp. 1-5, Nov. 2015.

[9] A. Kunwar, A. K. Gautam, and B. K. Kanaujia, "Inverted L-slot tripleband antenna with defected ground structure for WLAN and WiMAX applications," Int. J. Microw. Wireless Technol., Feb. 2, 2016

[10] H. Zhai, Z. Ma, Y. Han, and C. Liang,"A compact printed antenna for triple-band WLAN/WiMAX applications," IEEE Antennas Wireless Propag. Lett., vol. 12, pp. 65-69, Jan. 2013.

[11] W. Hu, Y.Z. Yin, P. Fei, and X. Yang,"Compact triband square-slot antenna with symmetrical L-strips for WLAN/WiMAX applications," IEEE Antennas Wireless Propag. Lett., vol. 10, no. pp. 462-465, May 2011.

[12] L. Dang, Z. Y. Lei, Y. J. Xie, G. L. Ning, and J. Fan, "A compact microstrip slot triple-band antenna for WLAN/WiMAX applications," IEEE Antennas Wireless Propag. Lett., vol. 9, pp. 1178-1181, Dec. 2010

[13] X.W. Dai, Z.Y. Wang, C.H. Liang, X. Chen, and L.T. Wang, "Multiband and dual-polarized omnidirectional antenna for $2 \mathrm{G} / 3 \mathrm{G} / \mathrm{LTE}$ application, IEEE Antennas Wireless Propag. Lett., vol. 12, pp.1492-1495, 2013

[14] F. Gao, P. Gao, T. Wu, and R. Shan, "Multi-band dual polarized indoor antenna for diversity and MIMO applications," PIERS Proc., pp.554557,2012

[15] L. Mouffok, A. C. Lepage, J. Sarrazin, and X. Begaud, "Compact dualband dual-polarized antenna for MIMO LTE applications," Int. J. Antenna Propag., vol. 2012, pp. 1-10, 2012.

[16] Andreas Peristerianos, Argiris Theopoulos, Anastasios. G. Koutinos, Theodoros Kaifas, "Dual-band fractal semi-printed element antenna arrays for MIMO applications," IEEE Antennas Wireless Propag. Lett., vol. 15, 2016:730-733

[17] W.H. Hsu, C.H. Wen, S.C. Pan, and H. Y. Jheng, IEEE Antennas Wireless Propag. Lett. "A tablet MIMO antenna with a wave-trap slot for LTE/WiMAX applications," Proceedings of the International Symposium on Antennas and Propagation (ISAP'13), pp. 1307-1310, Nanjing, China, October 2013.

[18] S. Shoaib, I. Shoaib,N. Shoaib, C. Xiaodong, and C. G. Parini, "A $4 \times 4$ MIMO antenna system for mobile tablets," Proceedings of the 8 th European Conference on Antennas and Propagation(EuCAP'14), pp. 2813-2816, The Hague, The Netherlands, April 20 